\title{
Management System Including Health Care and Marketing of Pigs Adopted by Farmers in Dhankuta and Terhathum Districts
}

\author{
R. P. Sah*, S. K. Jha and S. Karki \\ Agricultural Research Station, Pakhribas, Dhankuta \\ *Corresponding author: rpsnarc@yahoo.com
}

\begin{abstract}
Study was carried out to explore the management system of pig including health care and marketing, adopted by farmers in Hattikharka of Dhankuta and Phakchamara of Terhathum districts. A semi-structured questionnaire was distributed to a total of 200 pig farmers of selected sites. Farmers were surveyed to acquire information on management systems of pig such as, housing, breeding, feeding, health care and marketing. Majority of pig farmers kept Pakhribas black pig, chawanche and their crosses. Population of local pigs was found three times more than improved breeds in both sites. Generally, 1-5 pigs were raised by a farmer. Bamboo, wood and mud were mostly used as housing material. Stall feeding system was adopted by most of the farmers. Locally available feeding materials such as, rice bran, rice polish, maize, sisno, karklo, swill feeding, leftover food and green grasses like rayo, latte sag, kande jhar, twigs of fodder, khubhindo, pumpkin etc were mostly used for pig. Rai, Sherpa, Tamang, Gurung, Limbu, Magar, BK and Shrestha communities were mainly rearing pigs. Diarrhea, gastroenteritis, piglet mortality, agalactia, repeat breeding, parasitic infestation, etc were reported as the common diseases in pigs. Drenching against worm was adopted by few farmers and drugs like albendazole and fenbendazole were common. Vaccination against swine fever was also reported by the farmers and is in increasing trend as a preventive measure. According to farmers, demand for pigs is more than supply in the market and all the pigs are marketed and consumed within the district.
\end{abstract}

Keywords: Management system, health care, marketing, pig, Dhankuta and Terhathum

\section{INTRODUCTION}

Pig (Sus scrofa) farming enterprise is one of the important economic activities in Nepal. Livelihood, food and nutritional security and employment opportunities of several communities are also associated with pig husbandry. The population of pigs is estimated to be about 1.2 million $(1,203,230)$ heads in Nepal and pork meat production is 20,135 metric ton (CBS, 2016). Among which about $50 \%$ pig population 
is represented by Nepalese breeds, such as Pakhribas black, Chawanche, Hurrah and Bampudke, while the introduced breeds are Hampshire, Landrace, Tamworth, Yorkshire, Duroc etc. Management system includes housing, breeding, feeding and health care and marketing as well. Pakhribas black pig is a synthetic breed developed by Nepali scientists for higher production in the prevailing agro-ecological conditions, using three different breeds (Seddleback, Fayun and Tameworth).

Pig farming has been accepted socially and culturally by certain ethnic groups only. However, its trend is changing gradually due to urbanization. The farm size is usually smaller, but the commercialization has been started. In comparison to other livestock, crop cycle of pig farming is shorter. Generally, two farrowings per sow per year can be obtained having $8-12$ piglets in a single farrowing with maximum $15 \%$ piglet mortality during weaning period. Pig farming trend is increasing in Nepal due to reduced cultural biases against pigs and new government programs to support pig farming as a low cost means to create income for poverty alleviation and to improve food security. About $48 \%$ increase in the Nepal pig population in 14 years (MoAD, 2016) shows how fast this industry is growing. Pig farms are not homogeneously distributed in Nepal. Pig farming is most prevalent in the eastern and central regions of the country where the pig-raising ethnic community predominates and is also more common in peri-urban areas because of an increased demand of pig meat in urban areas. Hence, this study aims to represent the scenario of different existing systems associated with pigs and identify commonly occurring diseases in pigs in Dhankuta and Terhathum districts.

\section{MATERIALS AND METHODS}

In 2015-16, a survey was conducted to the pig farmers of different two places viz. Hattikharka (Figure 1A) and Phakchamara (Figure 1B) of Dhankuta and Terhathum districts, respectively. A semi-structured questionnaire was distributed to a total of 200 pig farmers of selected sites (100 from each). Required data were collected from District Livestock Service Office, Dhankuta and Terhathum. The questionnaire format included number of pigs, breeds, housing system, feeding system, health care, common diseases and marketing.

The data generated were stored in a Microsoft Excel spreadsheet (Microsoft Corporation) and descriptive analysis was performed. 


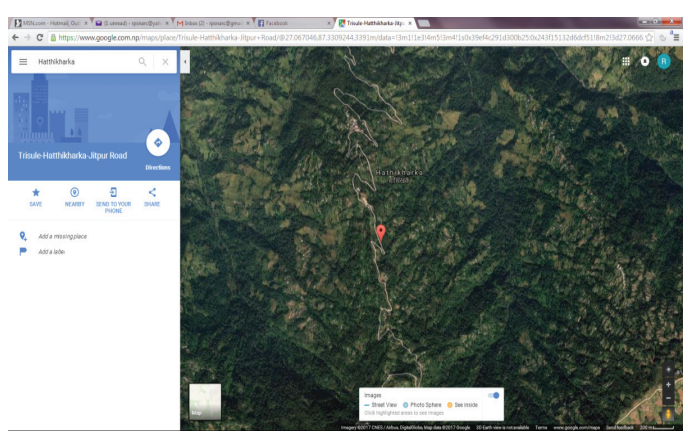

A.

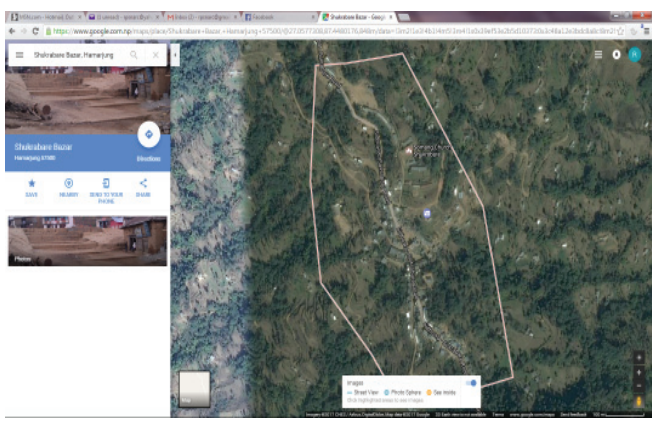

B.

Fig. 1: Map of study areas (A. Hattikharka of Dhankuta and B. Phakchamara of Terhathum) source: www.google.com/maps

\section{RESULTS AND DISCUSSION}

\section{Population of Pig}

Total population of pig in Dhankuta and Terhathum districts was presented in the following Table 1. Local breed was found two times more than other breeds (crosses, improved) of pig. Local breed included mainly pakhribas black pig, chawanche and Bandel.

Table 1: Population of pig in Dhankuta and Terhathum (in number)

\begin{tabular}{|c|c|c|c|}
\hline Breed/District & Local & Others (crosses, improved) & Total \\
\hline Dhankuta & 26,803 & 11,387 & 38,190 \\
\hline Terhathum & 21,697 & 13,158 & 34,855 \\
\hline Total & 48,500 & 24,545 & 73,045 \\
\hline
\end{tabular}

Source: Annual Report, DLSO, Dhankuta and Terhathum (FY 2072/73)

\section{Breeds of pigs}

It was found that $70 \%$ farmers raised indigenous/local breed followed by mixed (crosses of local and improved- 22\%) and improved breed (8\%) of pig as given in Figure 2. Population of indigenous pigs was found about 3 times more than mixed and improved breeds in both sites. Rearing more indigenous pigs might be due to tradition to raise black pigs and people like black color of pig. Indigenous breeds like pakhribas black and chawanche look like mainly black. Such breeds are also popular due to their positive attributes. Indigenous pigs are successfully reared in low investment as well as well adopted in Nepalese climate in comparison to exotic breeds. 


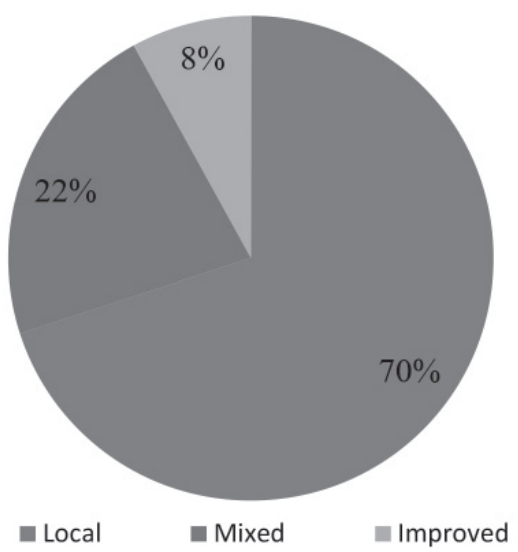

Fig. 2: Breeds of pigs raised by farmers

In this figure, people were encouraging towards rearing improved breeds also because of urbanization. Improved breeds included Hampshire, Yorkshire, Landrace, Duroc and Meishan.

\section{Pigs raised per household}

Most of the farmers were raised pig as an average of 2.5 pigs (range: 1-5 pigs) per household (Figure 3). It might be because farmers want to utilize their kitchen wastes, locally available grasses and other materials like kudo. This report is similar made by Joshi (2006) who stated that farmers kept 2-3 pigs per household. This also might be because few ethnic groups like Rai people rear pigs for their religious and ethnic value. But due to urbanization, people were encouraging towards commercial scale also.

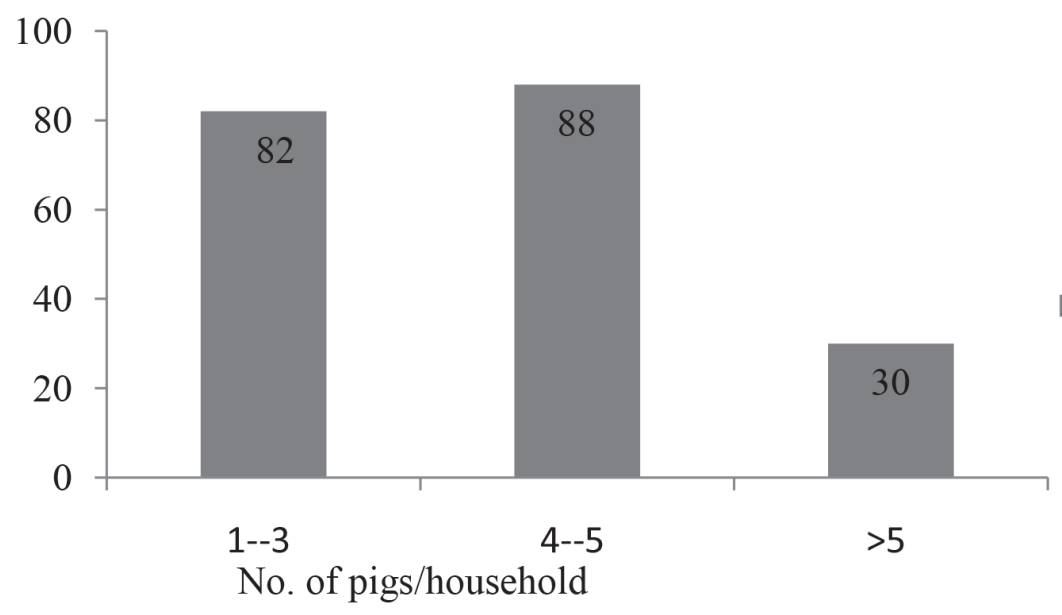

Fig. 3: Pigs raised by farmers 


\section{Housing system and materials}

Majority of pig sty/house (90\%) were made up of locally available materials like bamboo, wood and mud rather than concrete as shown in Figure 4. It is because of low economic status of people. People were showing interest to adopt semi-intensive and intensive housing system rather than free range. About 10\% people were raising pigs in concrete houses which indicate people are encouraging towards rearing pigs commercially.

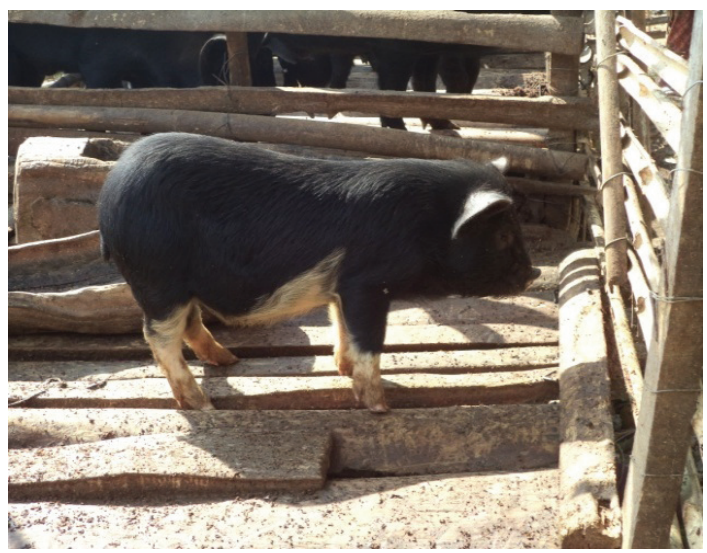

A.

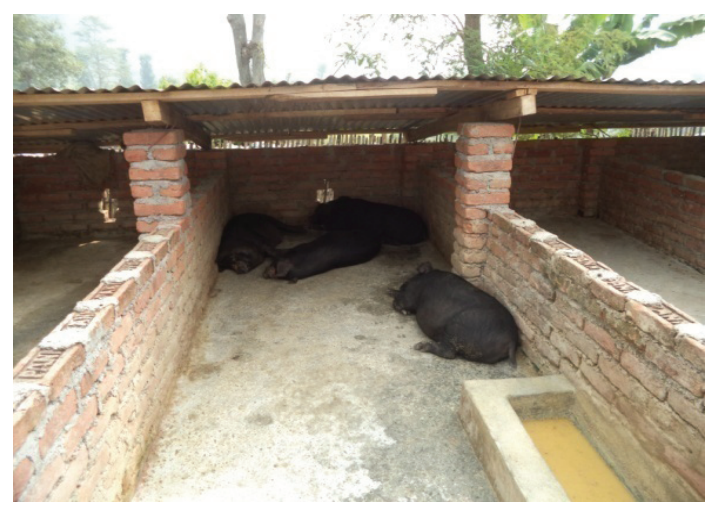

C.

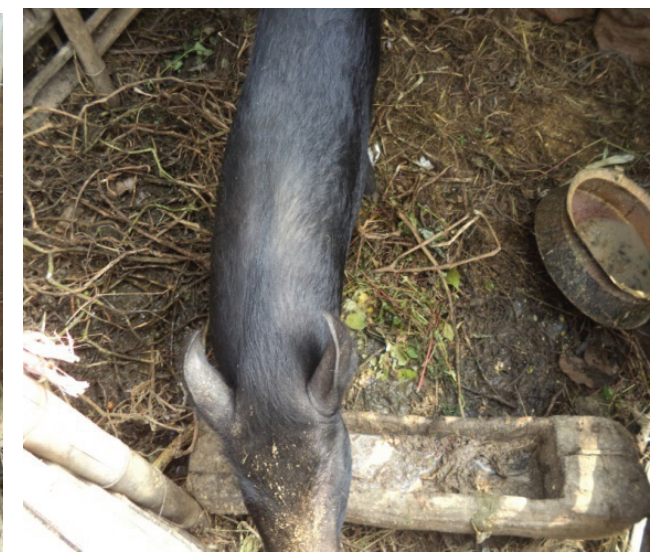

B.

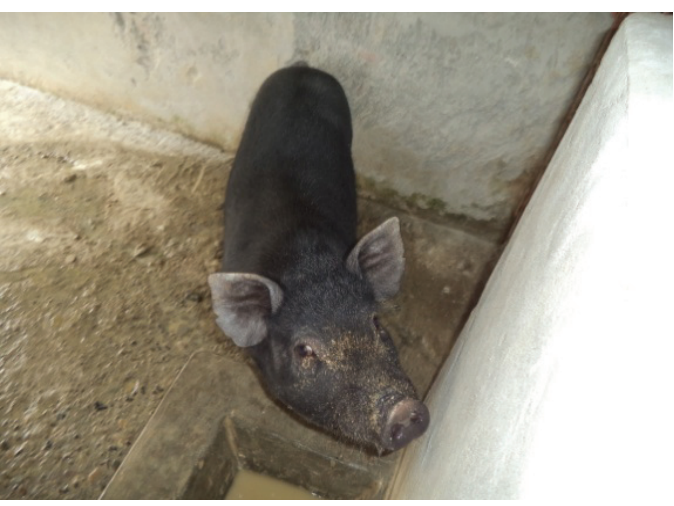

D.

Figure 4. Pigs raised under different management conditions (A, B: houses made up of bamboo, wood and mud; C, D: houses made up of concrete) 


\section{Feeding system}

Stall feeding system was adopted by majority of pig farmers $(98.5 \%)$ rather than others $(1.5 \%)$. Because it is easy to feed and utilize most of the waste materials as feed and family members also can give time to enough care.

Farmers used locally available feeding materials that were rice bran, rice polish, maize, sisno, karkalo, swill feeding, leftover feed from home/hotel and cooked food and green grasses like rayo, latte sag, kande jhar, twigs of fodder, khubhindo, pumpkin and other forages etc. Pig farmers used mainly above ingredients as feed because they want to get profit from their own resources.

\section{Pigs reared by different community}

Generally Rai, Sherpa, Tamang, Gurung, Limbu, Magar, BK and Shrestha communities were reported for rearing the pigs. Above ethnic group of people had been raising pigs since long ago. It was found that involvement of Rai people in pig rearing was 25\% that is followed by Sherpa (19\%) and Tamang, Gurung etc (Figure 5 ). It is said that ethnic groups like Rai caste people rear pigs for their religious and ethnic value. Involvement of Bahun and Kshetri to rear pigs was found nil.

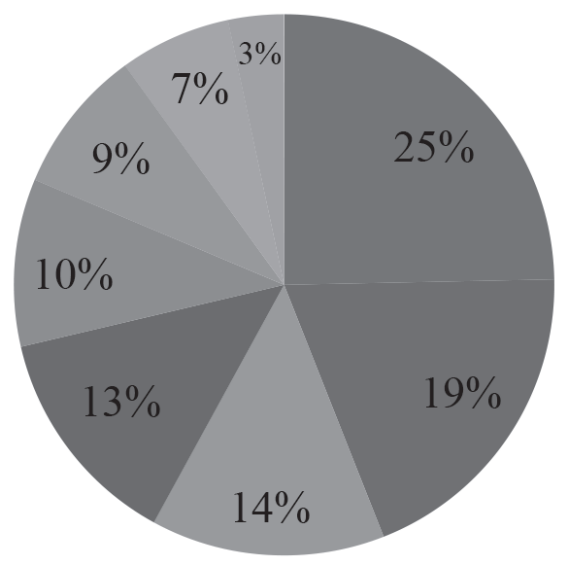

\section{Common diseases of pig}

According to respondents, the common diseases encountered in pigs were diarrhea, gastroenteritis, piglet mortality, agalactia, repeat breeding, parasitic infestation, abortion as given in Table 2. Among 200 respondents, $85 \%$ farmers faced problem of diarrhea. Similarly $81 \%$ farmers encountered gastroenteritis. These problems may be due to feeding of unbalanced, unhygienic feeding materials and internal parasite infestation. Piglet mortality might be due to coldness during parturition/newly born piglets, hypoglycaemia, iron deficiency, weakness of mother, low milk production. 
Nepalese Vet. J. 33:90- 97

Table 2: Common diseases of pigs

\begin{tabular}{|l|c|c|}
\hline Common diseases & Yes & \% \\
\hline Diarrhoea & 170 & 85 \\
\hline Gastroenteritis & 162 & 81 \\
\hline Piglet mortality & 153 & 76.5 \\
\hline Agalactia & 130 & 65 \\
\hline Parasitic infestation & 120 & 60 \\
\hline Abortion & 68 & 34 \\
\hline Others & 60 & 30 \\
\hline
\end{tabular}

Drenching against worm was being adopted by few farmers and the drugs were albendazole and fenbendazole. Vaccination against swine fever was being used, increasing in trend, for prevention. Iron injection for piglet was also being practiced frequently as prevention from piglet anemia and mortality.

\section{Marketing system}

There was no fixed system for marketing; however, there was a regular live animal and pork haat bazaar system developed in Dhankuta municipality and a few highway roadside bazaars to which farmers brought their live animals for sale to local traders. The traders then sold the pigs to the major traders or they sold to the butchers who slaughtered the pigs and sold the meat at retail meat shops. The major traders took the live pigs to other districts like Sunsari also. Sometimes farmers slaughtered the pigs in their own home and sold the meat nearby prefix consumers. Generally all the pork meat was consumed in Dhankuta and Terhathum districts.

\section{CONCLUSION}

Dhankuta and Terhathum districts have been seen as potential area of interest for pig farmers because supply is less than demand. Raising pigs towards commercial scale was increasing in trend and majority of people like black pigs. Also, people of different communities are raising pigs. Farmers need knowledge on proper method of mixing of ingredients and feeding practices so that they can get more profit from locally available ingredients. Awareness towards diseases prevention like parasitic diseases, piglet mortality should be provided to the farmers time to time. Encouragement towards deworming, vaccination and sanitation should be given to pig farmers 


\section{ACKNOWLEDGEMENTS}

Authors are grateful to field recorders of respective sites to help during survey in study areas in Dhankuta and Terhathum. We are also thankful to staffs of outreach research unit of ARS, Pakhribas and respective DLSOs for their cooperation during survey.

\section{REFERENCES}

CBS (Central Bureau of Statistics). 2016. National Sample Census of Agriculture, Nepal.

DLS (Department of Livestock Services). 2072-73. Annual Report of Department of Livestock Services (DLS), Dhankuta and Terhathum, Government of Nepal.

Joshi, D. D. (2006). Pig farming system in Nepal: how can research and development enhance benefits to the poor farmers of Nepal? NZFHRC, Kathmandu, Nepal. pp. $48-56$.

MOAD: (2016) Statistical information on Nepalese Agriculture (2072/73). Government of Nepal, Ministry of Agriculture Development. http://www. moad.gov.np/downloadfile/yearbook2016_1363677455.pdf. 